\title{
BMJ Open Productivity losses among people with back pain and among population-based references: a register-based study in Sweden
}

Filip Gedin (D) ,' Kristina Alexanderson, ${ }^{2}$ Niklas Zethraeus, ${ }^{1}$ Korinna Karampampa ${ }^{2}$

To cite: Gedin F, Alexanderson K, Zethraeus N, et al. Productivity losses among people with back pain and among population-based references: a register-based study in Sweden. BMJ Open 2020;10:e036638. doi:10.1136/ bmjopen-2019-036638

- Prepublication history for this paper is available online. To view these files, please visit the journal online (http://dx.doi. org/10.1136/bmjopen-2019036638).

Received 23 December 2019 Revised 17 June 2020 Accepted 30 June 2020
Check for updates

\section{(C) Author(s) (or their} employer(s)) 2020. Re-use permitted under CC BY-NC. No commercial re-use. See rights and permissions. Published by BMJ.

${ }^{1}$ Department of Learning, Informatics, Management and Ethics, Karolinska Institutet,

Stockholm, Sweden

${ }^{2}$ Department of Clinical Neuroscience, Karolinska Institutet, Stockholm, Sweden

Correspondence to

Filip Gedin; Filip.gedin@ki.se

\section{ABSTRACT}

Objective Back pain is the leading cause for years lived with disability globally and among the main reasons for sickness absence (SA) and disability pension (DP). The objective of this study was to explore the occurrence of SA and DP and to estimate productivity losses among individuals with back pain compared with among matched population-based references.

Design Explorative prospective cohort study using register microdata.

Participants and setting A total of 23176 people, aged 19-60 years, with a first visit to inpatient or specialised outpatient healthcare for back pain (International Statistical Classification of Diseases and Related Health Problems code M54) in 2010 in Sweden and a matched populationbased reference group $(n=115880)$.

Outcomes Long-term SA (in SA spells $>14$ days) and DP and productivity losses, measured in $€$ (2018 prices) by multiplying the SA and DP net days by the societal cost of each such day.

Results In the back-pain group, $42 \%$ had SA or DP days; in the reference group, the corresponding proportion was $15 \%$. Productivity loss per patient with back pain was $€ 8928$ during the 12-month follow-up period; in the reference group, it was $€ 3499(p<0.0001)$.

Conclusions SA and DP, leading to excess productivity losses among people with back pain, reflect the challenges these patients are facing to maintain their work capacity. Interventions to promote that individuals with back pain remain in paid work should be a priority in order to address the high costs.

\section{INTRODUCTION}

Today, back pain is one of the major public health problems among individuals of working age. ${ }^{1}$ The prevalence of back pain varies between $15 \%$ and $30 \%$ in different populations ${ }^{23}$ and the majority of adults will experience back pain at some point in their life. ${ }^{4}$ Low back pain is the most common type of back pain, with a lifetime prevalence of $84 \% .^{5}$

Back pain is a leading cause of years lived with disability (YLD), ${ }^{67}$ estimated as the prevalence of back pain multiplied by a disability
Strengths and limitations of this study

- Use of high-quality data from nationwide administrative registers covering all working aged individuals with incident specialised outpatient or inpatient healthcare for back pain $(n=23176)$ in an entire country; that is: no selection, no drop-outs and no self-reported data.

- A prospective population-based cohort study design.

- Use of a matched reference group five times the size of the studied population $(n=115880)$.

- Information about the first 14 days of sickness absence spells could not be included, meaning that the costs may be somewhat underestimated.

weight reflecting any short-term or long-term loss in health. ${ }^{8}$ The YLDs due to back pain have increased by $54 \%$ since the 1990 s, and were estimated at 60 million YLDs in 2015. ${ }^{9}$

Due to back pain, an individual's work capacity can be affected; in fact, back pain is ranked among the most frequent causes of short-term or permanent marginalisation from the labour market in terms of sickness absence (SA) and disability pension (DP). ${ }^{10}$ Chronic back pain (pain persisting more than 3 months) is often associated with productivity losses due to $\mathrm{SA},{ }^{11}{ }^{12}$ as well as a higher risk of being granted DP. ${ }^{13-15}$

The societal costs of low back pain, that is, all healthcare costs and productivity losses associated with the disease, were estimated at $€ 1860$ million in Sweden in 2001, with SA being the main cost driver. Among patients who were employed, $60 \%$ had at least 1 day of SA due to low back pain during a 3-month period. ${ }^{16}{ }^{17}$ According to the Swedish Social Insurance Agency, back pain was one of two diagnoses accounting for the largest proportion of total SA benefits (7\%) in 2011. ${ }^{18}$

There is a need to both update and expand our knowledge regarding SA, DP and productivity losses among people with back pain. In 
addition, no information is available showing the association of these three outcomes with multimorbidity, that is, individuals diagnosed with back pain also having other medical conditions.

The aim of this study was to explore the occurrence of SA and DP, and to estimate productivity losses among individuals with back pain compared with among matched references.

\section{METHODS}

A population-based explorative prospective cohort study was conducted, using microdata from four Swedish nationwide administrative registers, of people having had specialised outpatient or inpatient healthcare due to back pain. Data in the registers were linked using the unique personal identity numbers that all residents in Sweden have. ${ }^{19}$ The inclusion criteria for the back-pain group were:

- Aged 19-60 years in 2010, having lived in Sweden in 2005-2009.

- Having been diagnosed with back pain (International Statistical Classification of Diseases and Related Health Problems (ICD-10) code M54) ${ }^{20}$ as main diagnosis in inpatient or specialised outpatient healthcare in 2010.

- No previous inpatient or specialised outpatient healthcare for back pain as main or secondary diagnosis according to the National Patient Register (available since 1987 for inpatient healthcare and since 2001 for specialised outpatient healthcare).

A matched reference group was drawn from the general population in Sweden among all those who in 2010 were 19-60 years, had lived in Sweden in 2005-2009 and had no previous, current or in the 12 following month a main or secondary diagnoses of back pain (ICD-10 code M54) according to the National Patient Register. For each identified individual with back pain, five references were included, matched with regard to sex, age, type of living area and country of birth.

The four nationwide registers used were administrated by the following three authorities:

- Statistics Sweden: Longitudinal Integration Database for Health Insurance and Labour Market Studies, for information on age, sex (female/male), type of living area (big cities/medium-sized cities/rural areas), country of birth (Sweden/Nordic countries except Sweden/EU25 except Nordic countries/rest of the world), educational level (elementary school/ high school/university or college), occupation (white collar/blue collar/missing) and family situation (married or cohabitating without children at home/ married or cohabitating with children at home/single without children at home/single with children at home).

- Swedish Social Insurance Agency: MicroData for Analysis of the Social Insurance database: dates, main diagnosis and grade (full time or part time) of SA and DP.
- National Board of Health and Welfare: National Patient Register (dates and diagnoses for inpatient and specialised outpatient healthcare), Cause of Death Register (year of death).

Individuals with back pain were followed prospectively for 12 months from the date of the first inpatient stay or specialised outpatient healthcare event for back pain in 2010 (index date, $\mathrm{T}_{0}$ ). The matched references were also followed for 12 months after the index date. Individuals were censored at the year of death if that occurred before the end of the 12-month follow-up.

Individuals with at least one visit to inpatient or specialised outpatient healthcare in the 12 months before $T_{0}$ for other diagnoses than M54 were defined as having multimorbidity, except for healthcare with uncomplicated delivery (O80) and burn-out (Z73.0).

\section{Outcomes}

Information on long-term SA (SA spells $>14$ days) and on DP were used to calculate the number of SA/DP net days during the 12 months from $\mathrm{T}_{0}$ and forward.

All people living in Sweden, aged 16 years or above, with income from work or unemployment benefits, whose work capacity is reduced due to disease or injury can claim SA benefits. Day 1 is a waiting day, with $100 \%$ loss of income; from day 8, a medical certificate is required. The employer reimburses days 2-14, after which the Swedish Social Insurance Agency steps in. For individuals on unemployment benefits, the Swedish Social Insurance Agency reimburses SA benefits from day $2 .{ }^{21}$ In order not to introduce bias in relation to availability of SA data and employment status, only long-term SA spells $>14$ days were included in the analyses.

DP can be granted to people aged 19-64 years and living in Sweden, even if not having any income, if their work capacity is reduced long term or permanently due to disease or injury. ${ }^{21}$ The regular age for old-age pension was 65 years in 2012.

In Sweden, both SA and DP can be granted for full time $(100 \%)$ or part time $(75 \%, 50 \%$ or $25 \%)$ of ordinary work hours. ${ }^{21}$ This means that it is possible to have both partial SA and DP at the same time. Therefore, we calculated number of net days, for example, two absence days at $50 \%$ were combined into one net day. As a SA-spell could go on for years before DP was granted, long-term SA and DP days were combined (hereinafter, referred to as SA/DP).

The societal costs related to productivity losses (hereinafter referred to as productivity losses) for people with back pain and for the reference group were estimated using the human capital approach. ${ }^{22} 23$ Productivity losses were estimated by multiplying the percentage of work time lost due to SA/DP per year by the age-adjusted mean annual income (451 664 Swedish kronor (SEK) ${ }^{24}$ ) for each individual, including social security contributions from employers $(31.42 \%){ }^{25}$ The income was inflated to 2018 prices, using a harmonised index for consumer prices. ${ }^{26}$ To increase comparability, these data were converted from SEK to $€$ at 2018 values $(10.2567 \mathrm{SEK}=€ 1)$. 


\section{Analyses}

Descriptive analyses were conducted for the sociodemographic and multimorbidity characteristics, as well as to estimate the mean number of SA/DP days and productivity losses during the 12 months following the index date $\mathrm{T}_{0}$, for both the patients with back pain and the reference group.

Since SA/DP is associated with a variety of sociodemographic factors, ${ }^{27-31}$ analyses of SA/DP were stratified based on the following sociodemographic variables: sex, age, type of living area, country of birth, educational level, occupational group and family situation.

In addition, SA/DP during the 12-month follow-up was estimated for each of the following six different multimorbidity diagnostic groups: other musculoskeletal disorder (other M than M54), depressive disorder (F32-F34), other mental disorders (other F and Z73.0), neoplasms (C00-D48), diseases of the circulatory system (I00-I99) and other (all others, excluding E10-E14, Z73.0 and O80).

The Pearson's $\chi^{2}$ test was used to explore possible differences in the distribution of demographic and multimorbidity characteristics between the back pain and the reference groups (between-group comparison, see table 1). ${ }^{32}$

Another between-group comparison was performed to identify the difference of costs between the back-pain group and the references with regards to demographic, socioeconomic and multimorbidity characteristics; this comparison was made using a two-tailed t-test with unequal variances (statistical significance: $\alpha<0.0001$ ). Two in-group comparisons were performed-one regarding differences in productivity losses between women and men in the back-pain group, and the other exploring the impact of multimorbidity on productivity losses, when already diagnosed with back pain. These comparisons were performed using a two-tailed t-test with unequal variances (statistical significance: $\alpha<0.0001$ ).

\section{Patient and public involvement}

Patients and the public were not involved in this registerbased study.

\section{RESULTS}

In all, 23176 individuals with back pain and 115880 matched references were included in the analyses. A higher proportion of the individuals with back pain had lower educational level and blue collar occupations (table 1). Regarding multimorbidity, the cohort of patients with back pain had significantly higher proportions of people with other musculoskeletal disorders $(42 \%)$ and mental disorders $(26 \%)$ compared with the reference group (19\% and $14 \%$, respectively).

The mean number of SA/DP days during the 12-month follow-up was 74 among the individuals with back pain and 29 among those in the reference group (table 2). The majority of individuals in both the back pain and the reference groups had no SA/DP days. Nonetheless, the back-pain group had a larger proportion of individuals with 15-249 SA/DP days during the 12 months following $\mathrm{T}_{0}(28 \%)$, compared with the reference group (9\%; figure 1). In addition, the back-pain cohort had a higher proportion of individuals with $\geq 250$ SA/DP days. In the back-pain cohort, $52 \%$ of the total net SA/DP days were with DP; the corresponding number was $70 \%$ in the reference group. The proportion among the patients with back pain of women and men with back pain in blue collar occupations was about the same: $54.09 \%$ and $54.70 \%$, respectively. The corresponding proportions among the references were $50.18 \%$ and $49.77 \%$, respectively.

The productivity loss per individual with back pain was $€ 8928$, compared with $€ 3499(\mathrm{p}<0.0001)$ in the reference group. Thus, having had specialised healthcare for a back pain diagnosis meant additional productivity losses of $€ 5429$ ( $\mathrm{p}<0.0001)$ during the 12 months following a first visit to specialised healthcare for back pain, compared with the references. An in-group comparison (not shown in table 2), testing the differences of costs between women and men in the back-pain group, revealed that costs for back pain were significantly higher among women $€ 10376$ than among men $€ 7239$ $(\mathrm{p}<0.0001)$.

The number of SA/DP days and thus, productivity losses, varied between the back-pain cohort and the references regarding both sociodemographic characteristics and multimorbidity (table 2, figure 2). The disease groups that accounted for the highest numbers of SA/ DP days for both the back pain and the reference groups were depressive disorder and other mental disorders. Individuals with both back pain and depressive disorder had $€ 4705$ higher costs compared with those in the reference group.

Within the back-pain group, people with both back pain and depressive disorder or other mental disorders, in general, had more SA/DP days and productivity losses than those patients in the back-pain group with no other diagnoses than back pain $(\mathrm{p}<0.0001$; table 2$)$.

Figure 2 shows the mean productivity loss for both the back-pain group and the reference group, as well as for people with multimorbidity, also showing what diagnoses categories that accounted for most productivity losses. The proportion of mean productivity losses (as seen in figure 2) was evenly distributed between the diagnostic categories. However, when we subgrouped, based on depressive disorder and other mental disorders, the results were skewed, with about $50 \%-70 \%$ of the costs attributed to $\mathrm{F}$ diagnoses (data not shown in figure 2). The largest differences in costs between the back-pain group and the reference group occurred among individuals with both back pain and neoplasms (C00-D48); they had $€ 6877$ higher costs compared with their references $(\mathrm{p}<0.0001)$. 
Table 1 Sociodemographic characteristics and multimorbidity of the cohort of people aged 19-60 years with specialised healthcare for back pain $(n=23176)$ and their matched references $(n=115880)$.

\begin{tabular}{|c|c|c|c|}
\hline & \multirow{2}{*}{$\begin{array}{l}\text { Back pain group } \\
\mathrm{n}(\%)\end{array}$} & \multirow{2}{*}{$\begin{array}{l}\text { Reference group } \\
\mathrm{n}(\%)\end{array}$} & \multirow[b]{2}{*}{ P value from Pearson's $\chi^{2}$ test) } \\
\hline & & & \\
\hline \multicolumn{3}{|l|}{ Sex } & n.a. \\
\hline Women & $12161(52.47)$ & $60805(52.47)$ & \\
\hline Men & $11015(47.53)$ & $55075(47.53)$ & \\
\hline \multicolumn{3}{|l|}{ Age } & n.a. \\
\hline 19-29 years & $3909(16.87)$ & $19545(16.87)$ & \\
\hline $30-39$ years & $5386(23.24)$ & $26930(23.24)$ & \\
\hline $40-49$ years & $6870(29.64)$ & $34350(29.64)$ & \\
\hline $50-60$ years & $7011(30.25)$ & $35055(30.25)$ & \\
\hline \multicolumn{3}{|l|}{ Educational level } & $<0.0001$ \\
\hline Elementary school* & $4344(18.74)$ & $16710(14.42)$ & \\
\hline High school & $11957(51.59)$ & 55509 (47.90) & \\
\hline University/college & $6875(29.66)$ & 43661 (37.68) & \\
\hline \multicolumn{3}{|l|}{ Type of living area } & n.a. \\
\hline Big cities & $10050(43.36)$ & $50250(43.36)$ & \\
\hline Medium-sized cities & $7530(32.49)$ & 37650 (32.49) & \\
\hline Rural areas & $5596(24.15)$ & $27980(24.15)$ & \\
\hline \multicolumn{3}{|l|}{ Country of birth } & n.a. \\
\hline Sweden & $18311(79.01)$ & $91555(79.01)$ & \\
\hline Nordic countries & $659(2.84)$ & $3295(2.84)$ & \\
\hline \multicolumn{4}{|l|}{ (except Sweden) } \\
\hline EU 25 (excluding Nordic countries) & $541(2.33)$ & $2705(2.33)$ & \\
\hline Rest of the world & $3665(15.81)$ & $18325(15.81)$ & \\
\hline \multicolumn{3}{|l|}{ Occupational group } & $<0.0001$ \\
\hline White collar & $7295(31.48)$ & $43161(37.25)$ & \\
\hline Blue collar & $12603(54.38)$ & 57925 (49.99) & \\
\hline Missing & $3278(14.14)$ & $14794(12.77)$ & \\
\hline \multicolumn{3}{|l|}{ Family situation } & $<0.0001$ \\
\hline Married/cohabitant without children at home & $2775(11.97)$ & $13422(11.58)$ & \\
\hline Married/cohabitant with children at home & $9442(40.74)$ & $48789(42.10)$ & \\
\hline Single without children at home & $8575(37)$ & $44223(38.16)$ & \\
\hline Single with children at home & $2384(10.29)$ & $9446(8.15)$ & \\
\hline \multicolumn{3}{|l|}{ DP at index date } & n.a. \\
\hline M54 & 221 & 375 & \\
\hline Other M & 840 & 1762 & \\
\hline F or Z74 & 957 & 3392 & \\
\hline Other & 988 & 3083 & \\
\hline \multicolumn{3}{|c|}{ Inpatient or specialised outpatient healthcare for different diagnoses in the 12 preceding months } & $<0.0001$ \\
\hline Back pain (M54) & $23176(100)$ & $0(0)$ & \\
\hline Other musculoskeletal disorders (other M) & $9770(42.15)$ & $21483(18.53)$ & \\
\hline Depressive disorder (F32-F34) & 1875 (8.09) & $4680(4.04)$ & \\
\hline Other mental disorders (other F†) & $4130(17.82)$ & $11103(9.58)$ & \\
\hline Neoplasms (C00-D48) & $3806(16.42)$ & $1458(12.59)$ & \\
\hline Diseases of the circulatory system (I00-199) & $3668(15.83)$ & $11586(10.01)$ & \\
\hline Otherł & 21787 (94.01) & 98984 (85.42) & \\
\hline
\end{tabular}

Those in the reference group were matched on age, sex, type of living area and country of birth with the back-pain group. Therefore, it was not relevant to report $p$ values for these variables ( $p$ values not shown in the table). Instead, $p$ values are shown for the variables that were not used for matching. Between-group comparisons were performed using the Pearson's $\chi^{2}$ test; that is, in this comparison, we explore the possible differences in the distribution of demographic and multimorbidity characteristics between the back-pain and the reference groups.

*Includes missing information on level of educational level, for back pain: 129 individuals and 997 individuals in the reference group.

tIncluding Z73.0.

fExcluding missing data, $\mathrm{Z} 73.0$ and $\mathrm{O} 80$

DP, disability pension; n.a., not applicable. 
Table 2 Mean number of sickness absence (SA)/disability pension (DP) net days and mean productivity losses per individual, among 23176 people with incident back pain in 2010 and 115880 matched references, in the 12 months after inclusion, for all those included, and in relation to sociodemographic characteristics and multimorbidity.

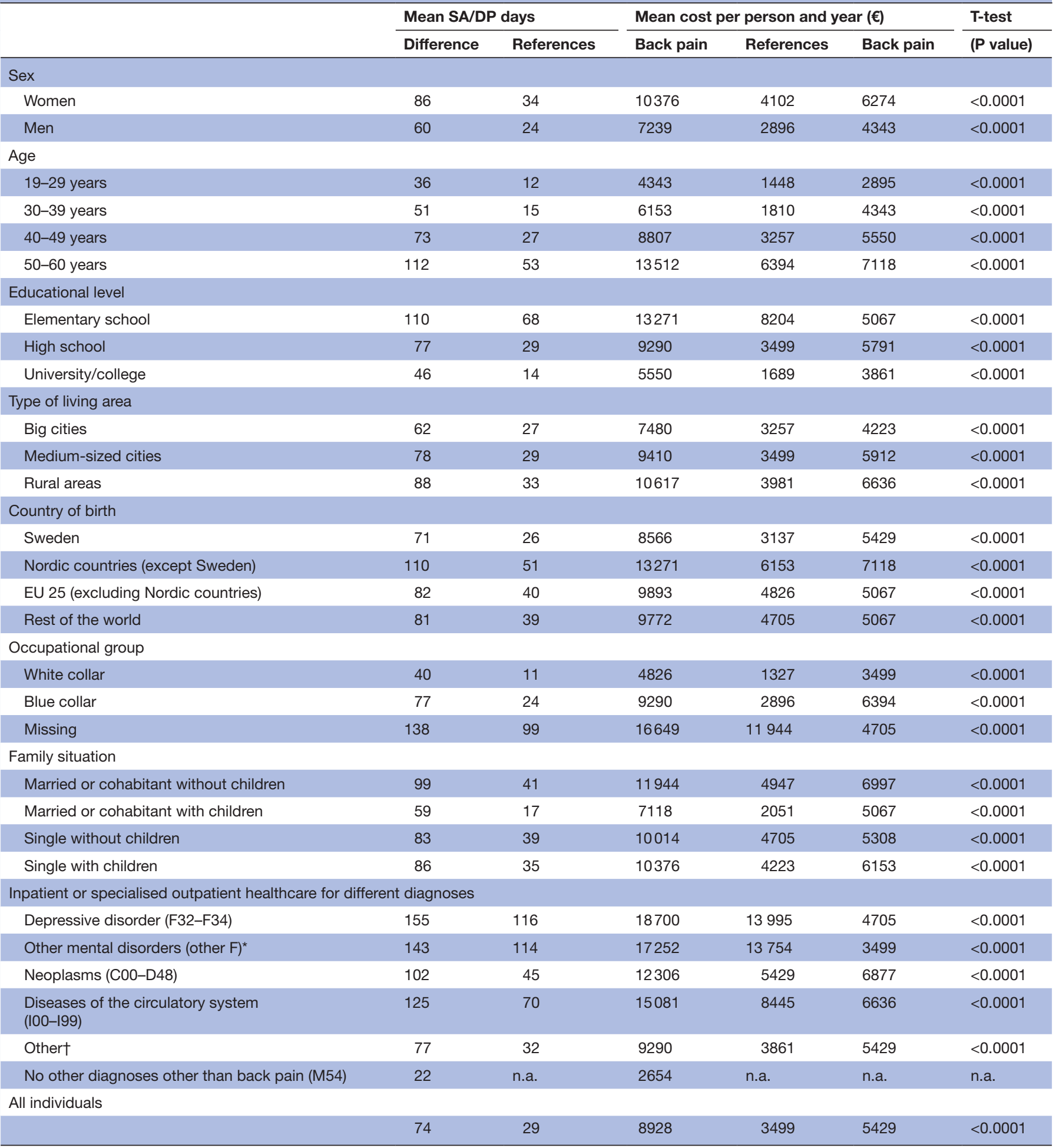

Inpatient or specialised outpatient healthcare for different diagnoses was defined in the 12 months before inclusion in the cohorts. The presence of depressive and other mental disorders, neoplasms, diseases of the circulatory system or other diseases was defined using International Statistical Classification of Diseases and Related Health Problems information from National Patient Register (secondary healthcare). For patients with back pain, these diagnoses were assumed to be in addition to the back pain diagnosis the patients had. Information for patients with back pain without any other diagnoses is also presented in this table (not relevant for the reference population).

*Including Z73.0.

†Excluding missing data, Z73.0 and O80.

n.a., not applicable. 


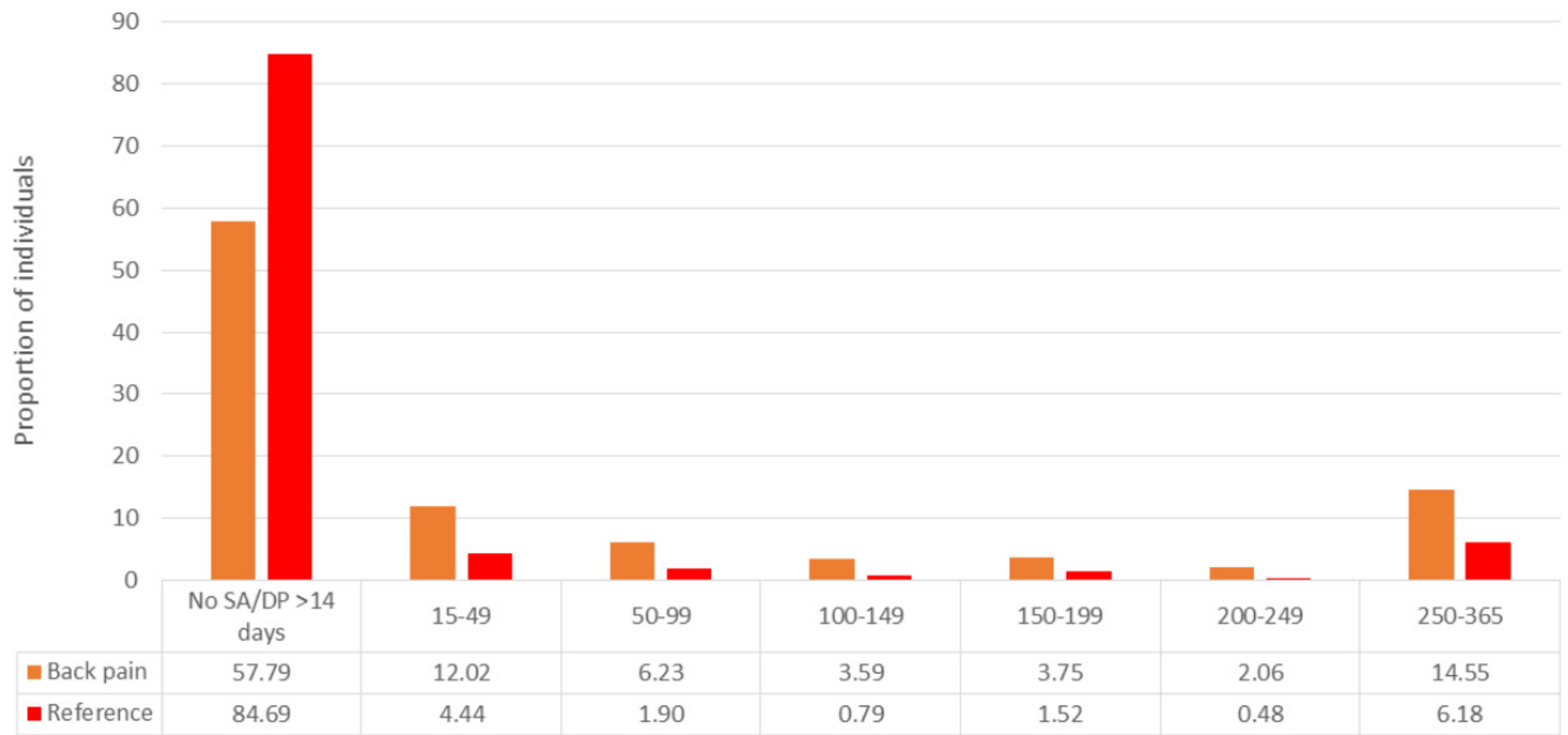

Figure 1 Proportions (\%) of patients with back pain and matched references, respectively, with different number of sickness absence (SA)/disability pension (DP) days in the 12 months following the diagnosis date.

\section{DISCUSSION}

In this explorative prospective cohort study based on data obtained from nationwide registers in Sweden, we found that individuals of working age with a first specialist healthcare visit for back pain had 45 more SA/DP days during the 12-month follow-up period, compared with the matched reference group drawn from the general population of Sweden. This translates into excess annual productivity losses of $€ 5429 /$ individual. However, not all had SA/DP in the two groups; in the back-pain group, $42 \%$ and in the reference group $15 \%$ had at least some long-term SA/DP during the 12-month follow-up period.

Like previous studies based on selective survey samples from the UK and USA, ${ }^{30} 31$ this nationwide register-based study also found a difference between the back-pain group and the reference group regarding their attained educational level and occupation. Those in the back-pain cohort generally had a lower educational level compared with the matched references. In addition, the proportion of blue collar workers was significantly higher in the back-pain cohort compared with the references. One of the suggested mechanisms for the correlation between low education and back pain is that healthcare tends to be unavailable or not adequately targeted to people with low education and back pain. ${ }^{33}$ However, this inequality is not as present in Sweden as in many other healthcare systems. ${ }^{34}$ Occupational and behavioural risk factors have also been suggested as possible underlying mechanisms. ${ }^{33}$ Nonetheless, none of these mechanisms can fully explain this correlation and low educational level is an important risk factor on its own. ${ }^{33}$

With regards to occupation, individuals in manual occupations are at higher risk of developing severe back pain than individuals in white collar work. ${ }^{30}$ Being exposed to physical workload can be associated with disabling back pain, which white collar occupations are not. ${ }^{30}$ It is also plausible that individuals with back pain who perform manual work struggle to return to physically demanding work tasks before quite ready for that.

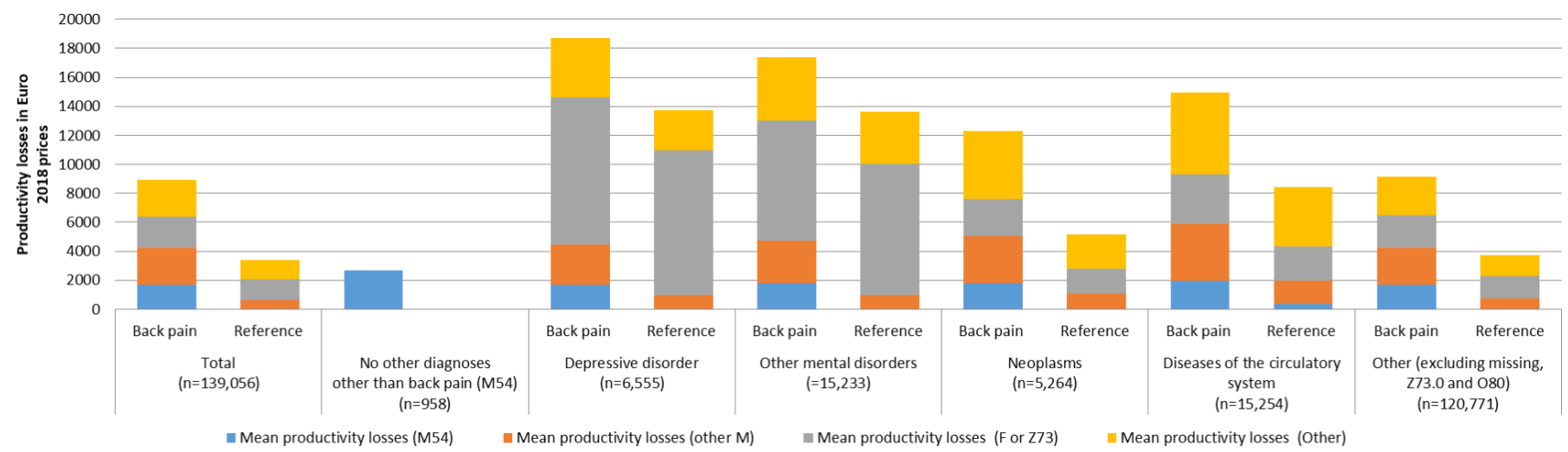

Figure 2 Mean productivity losses for the patients with back pain and the references, respectively, among all and for those with various types of multimorbidity. The coloured bars show the mean amount of productivity loss for each disease category. 
When comparing the SA/DP net days and productivity losses between the group of patients with back pain and that of references, the mean productivity losses/year per individual with back pain was $€ 5429$ higher than for the references. While we measured only productivity loss costs in this study, not medication, nor healthcare costs, it is known that approximately $84 \%$ of the total costs for back pain are attributed to productivity losses. ${ }^{17}$ In a recent cost-of-illness study of individuals with low back pain in the Västra Götaland region in Sweden, ${ }^{35}$ the mean cost per individuals following one episode of low back pain was $€ 2753$.

In an in-group comparison, we explored how gender correlated with productivity losses from back pain, since previous studies have shown that women tend to have higher rates of both long-term SA and DP. ${ }^{136}$ This finding from previous studies is also in line with our study, where women with back pain had a mean productivity loss $€ 1931$ higher than men with back pain. The reasons for women having more SA/DP are not fully understood. ${ }^{136}$ Generally, more women report back pain. ${ }^{2}$ Still, many jobs are structured, also including detailed work tasks, with the male body and strength as the norm. ${ }^{37}{ }^{38}$ In Sweden, the employment frequency of women is very high, also in higher ages, and a large rate of the women work in blue collar occupations-occupations that often involve high physical workloads, for example, as auxiliary nurses.

Further, in another in-group comparison, we explored the associations between multimorbidity and productivity loss among individuals with back pain. Individuals with back pain, with at least one other diagnosis, in general had greater productivity losses than individuals that only had a back-pain diagnose. These findings were consistent with the results from two previous studies on multimorbidity and SA. ${ }^{149}$ Moreover, individuals with back pain with a depressive disorder or other mental disorder had the highest mean productivity losses in the back-pain cohort. It is well established that depression is a risk factor for developing chronic back pain. ${ }^{29}{ }^{40}$ Dorner et al point out the importance of proper diagnostics and treatment of both conditions in order to avoid long-term SA and, in worst cases, $\mathrm{DP}^{39}$

\section{Strengths and limitations}

The main strengths of this study are the use of data from high-quality nationwide registers, the prospective cohort design and the use of a large cohort with matched references, allowing subgroup analysis based on a wide variety of sociodemographic and multimorbidity aspects. The complete dataset enabled the inclusion of all people with a visit to specialist healthcare for a back-pain diagnosis in 2010, thereby eliminating selection bias. Another benefit of having access to the nationwide registers is the possibility to establish a matched reference group. The matched reference group allowed us to demonstrate the excess productivity loss in the population with back pain in Sweden. Another strength was that net days of SA and DP could be calculated. The use of administrative data regarding all SA spells $>14$ days and all DP days ${ }^{41}$ allowed detailed calculations of the productivity losses without recall bias.

We did not have information about primary healthcare visits, which can be seen as a limitation, as we missed people with less severe back pain and as a strength as we had the more severe cases. Since we lack primary healthcare data, it is possible that some of the individuals in the reference group could have had back pain, however, not severe enough to require specialised, secondary healthcare. Another limitation is the lack of information on SA spells $\leq 14$ days. Thus, the cost estimates are conservative and likely underestimate the number of SA days, as most SA spells for individuals with back pain would probably be shorter than 14 days. ${ }^{42}$ Another limitation is the lack of information on the severity of back pain and other morbidities. The difference between mild and severe symptoms of back pain could play a major role when predicting the productivity losses from back pain.

This is the first study on productivity losses where nationwide register data have been used. Assumptions due to incomplete data play a lesser role in the analysis when the dataset provides a complete overview of the population. Thus, descriptive analyses were used to analyse the occurrence of SA/DP days in the groups. The data have been stratified in order to evaluate SA/DP in different socioeconomic and multimorbidity groups. We believe that these results provide valuable insight to the productivity losses of back pain in Sweden. Nevertheless, an important limitation to the descriptive analysis is the risk of confounders effects. Therefore, future research should adjust for potential confounders in order to improve the accuracy of our results.

\section{CONCLUSION}

We found that individuals with back pain had substantially higher productivity losses when compared with matched references without back pain; their productivity losses were 2.6 times higher, which amounts to $€ 5429$ more per year and individual. This can indicate that more needs to be done in order to help individuals with back pain to remain in or return to work.

Contributors All authors contributed to the conceptualisation of the research questions, the study design and the methods. FG performed the analyses of the data, interpreted the study findings and drafted the manuscript. KK, NZ and $\mathrm{KA}$ assisted in the interpretation of the study findings and contributed to the manuscript with comments/suggestions and text. All authors have read and approved the final version of the manuscript.

Funding This study was financially supported by the Swedish Research Council for Health, Working Life and Welfare, and by the Scandinavian College of Chiropractic.

Competing interests None declared.

Patient consent for publication Not required.

Ethics approval The project was approved by the Regional Ethical Review Board of Stockholm.

Provenance and peer review Not commissioned; externally peer reviewed.

Data availability statement Data may be obtained from a third party and are not publicly available. The data used in this study is administered by the Division of 
Insurance Medicine, Karolinska Institutet, and cannot be made public. According to the General Data Protection Regulation, the Swedish Act SFS 2018:218, the Swedish Data Protection Act, the Swedish Ethical Review Act and the Swedish Public Access to Information and Secrecy Act, this type of sensitive data can only be made available, after legal review, to researchers who meet the criteria for access to this type of sensitive and confidential data. Readers may contact Professor Kristina Alexanderson (kristina.alexanderson@ki.se) regarding the data.

Open access This is an open access article distributed in accordance with the Creative Commons Attribution Non Commercial (CC BY-NC 4.0) license, which permits others to distribute, remix, adapt, build upon this work non-commercially, and license their derivative works on different terms, provided the original work is properly cited, appropriate credit is given, any changes made indicated, and the use is non-commercial. See: http://creativecommons.org/licenses/by-nc/4.0/.

\section{ORCID iD}

Filip Gedin http://orcid.org/0000-0002-8408-5106

\section{REFERENCES}

1 Hartvigsen J, Hancock MJ, Kongsted A, et al. What low back pain is and why we need to pay attention. Lancet 2018;391:2356-67.

2 Hoy D, Bain C, Williams G, et al. A systematic review of the global prevalence of low back pain. Arthritis Rheum 2012;64:2028-37.

3 Walker BF. The prevalence of low back pain: a systematic review of the literature from 1966 to 1998. J Spinal Disord 2000;13:205-17.

4 Lemeunier N, Leboeuf-Yde C, Gagey O. The natural course of low back pain: a systematic critical literature review. Chiropr Man Therap 2012;20:33.

5 Balagué F, Mannion AF, Pellisé F, et al. Non-Specific low back pain. The Lancet 2012;379:482-91.

6 Vos T, Flaxman AD, Naghavi M, et al. Years lived with disability (YLDs) for 1160 sequelae of 289 diseases and injuries 1990-2010: a systematic analysis for the global burden of disease study 2010 . Lancet 2012;380:2163-96.

7 Alexanderson K, Norlund A. Swedish Council on technology assessment in health care (SBU). Chapter 1. AIM, background, key concepts, regulations, and current statistics. Scand J Public Health Suppl 2004;63:12-30.

8 Murray CJL, Atkinson C, Bhalla K, et al. The state of US health, 1990-2010: burden of diseases, injuries, and risk factors. JAMA 2013;310:591-608.

9 GBD 2015 DALYs and HALE Collaborators. Global, regional, and national disability-adjusted life-years (DALYs) for 315 diseases and injuries and healthy life expectancy (HALE), 1990-2015: a systematic analysis for the global burden of disease study 2015. Lancet 2016;388:1603-58.

10 Hansson T, Jensen I. Swedish Council on technology assessment in health care (SBU). Chapter 6. sickness absence due to back and neck disorders. Scand J Public Health Suppl 2004;63:109-51.

11 Breivik H, Collett B, Ventafridda V, et al. Survey of chronic pain in Europe: prevalence, impact on daily life, and treatment. Eur $J$ Pain 2006;10:287-333.

12 Jansson C, Mittendorfer-Rutz E, Alexanderson K. Sickness absence because of musculoskeletal diagnoses and risk of all-cause and cause-specific mortality: a nationwide Swedish cohort study. Pain 2012;153:998-1005

13 Alexanderson KAE, Borg KE, Hensing GKE. Sickness absence with low-back, shoulder, or neck diagnoses: an 11-year follow-up regarding gender differences in sickness absence and disability pension. Work 2005;25:115-24.

14 Alexanderson K, Kivimäki M, Ferrie JE, et al. Diagnosis-specific sick leave as a long-term predictor of disability pension: a 13-year follow-up of the GAZEL cohort study. J Epidemiol Community Health 2012;66:155-9.

15 Ropponen A, Svedberg P, Kalso E, et al. A prospective twin cohort study of disability pensions due to musculoskeletal diagnoses in relation to stability and change in pain. Pain 2013;154:1966-72.

16 Ekman M, Jönhagen S, Hunsche E, et al. Burden of illness of chronic low back pain in Sweden: a cross-sectional, retrospective study in primary care setting. Spine 2005;30:1777-85.

17 Ekman M, Johnell O, Lidgren L. The economic cost of low back pain in Sweden in 2001. Acta Orthop 2005;76:275-84.
18 Lidwall U. Vad kostar olika sjukdomar i sjukförsäkringen? [What are the costs for different diseases in Swedish sickness insurance?], Social Insurance Report 2011. 4,. Swedish Social Insurance Agency, 2011.

19 Ludvigsson JF, Otterblad-Olausson P, Pettersson BU, et al. The Swedish personal identity number: possibilities and pitfalls in healthcare and medical research. Eur J Epidemiol 2009;24:659-67.

20 WHO. International statistical classification of diseases and related health problems 10th revision (ICD-10), 2016. Available: https://icd. who.int/browse10/2016/en [Accessed 28 Aug 2019].

21 Swedish Social Insurance Agency [Försäkringskassan]. Social insurance in figures 2017. Stockholm: Swedish Social Insurance Agency, 2017.

22 Drummond M, Sculpher M, Torrance G, et al. Methods for the economic evaluation of health care programmes. Oxford University Press, 2015.

23 Tarricone R. Cost-Of-Illness analysis. Health Policy 2006;77:51-63.

24 Statistics Sweden. Average salary, by sector, occupation, age, sex and year statistics Sweden, 2010. http://www.statistikdatabasen.scb. se/pxweb/sv/ssd/START AM AM0110 AM0110A/LonYrkeAlder4/ table/tableViewLayout1/?rxid=26290d43-4316-43a7-915eca6b2cdd0b80

25 Hansson I. Tax statistical yearbook of Sweden 2010. 11 ed. Swedish Tax Agency, 2011.

26 Eurostat. Annual exchange rates (ECU/EUR exchange rates versus national currencies). Available: http://appsso.eurostat.ec.europa. eu/nui/show.do?dataset=prc_hicp_aind\&lang=en [Accessed $24 \mathrm{Apr}$ 2019].

27 Taylor JB, Goode AP, George SZ, et al. Incidence and risk factors for first-time incident low back pain: a systematic review and metaanalysis. Spine J 2014;14:2299-319.

28 Ferreira PH, Beckenkamp P, Maher CG, et al. Nature or nurture in low back pain? results of a systematic review of studies based on twin samples. Eur J Pain 2013;17:957-71.

29 Currie SR, Wang J. More data on major depression as an antecedent risk factor for first onset of chronic back pain. Psychol Med 2005;35:1275-82.

30 Lacey RJ, Belcher J, Croft PR. Does life course socio-economic position influence chronic disabling pain in older adults? a general population study. Eur J Public Health 2013;23:534-40.

31 Shmagel A, Foley R, Ibrahim H. Epidemiology of chronic low back pain in US adults: data from the 2009-2010 National health and nutrition examination survey. Arthritis Care Res 2016;68:1688-94.

32 Myers JL, Well AD, Lorch RF. Research design and statistical analysis. Third edn. Taylor \& Francis, 2013.

33 Dionne CE, Von Korff M, Koepsell TD, et al. Formal education and back pain: a review. $J$ Epidemiol Community Health 2001;55:455-68.

34 van Doorslaer E, Wagstaff A, van der Burg $\mathrm{H}$, et al. Equity in the delivery of health care in Europe and the US. $J$ Health Econ 2000;19:553-83.

35 Olafsson G, Jonsson E, Fritzell P, et al. Cost of low back pain: results from a national register study in Sweden. Eur Spine $J$ 2018;27:2875-81.

36 Allebeck P, Mastekaasa A. Swedish Council on Technology Assessment in Health Care (SBU). Chapter 5. Risk factors for sick leave - general studies. Scand J Public Health Suppl 2004;63:49-108.

37 Marklund S. Worklife and health in Sweden 2000. Stockholm: Swedish Work Environment Authority, 2001.

38 Östlin P. Gender inequalities in occupational health. Harvard School of Public Health: Harvard, 2001.

39 Dorner TE, Alexanderson K, Svedberg P, et al. Sickness absence due to back pain or depressive episode and the risk of all-cause and diagnosis-specific disability pension: a Swedish cohort study of 4,823,069 individuals. Eur J Pain 2015;19:1308-20.

40 Power C, Frank J, Hertzman C, et al. Predictors of low back pain onset in a prospective British study. Am J Public Health 2001:91:1671-8.

41 Ludvigsson JF, Andersson E, Ekbom A, et al. External review and validation of the Swedish national inpatient register. BMC Public Health 2011:11:450.

42 Henschke N, Maher CG, Refshauge KM, et al. Prognosis in patients with recent onset low back pain in Australian primary care: inception cohort study. BMJ 2008;337:a171. 